\title{
Ikeda revisited
}

\author{
Carl-Johan Söder ${ }^{1}\left[\right.$. Anders Rosén ${ }^{2} \cdot$ Mikael Huss $^{1}$
}

Received: 6 February 2017 / Accepted: 28 October 2017 / Published online: 29 November 2017

(c) The Author(s) 2017. This article is an open access publication

\begin{abstract}
In this paper Ikeda's method for roll damping prediction is revisited and the applicability of the method to modern volume carriers is considered. For volume carriers the hull lift and bilge keel components are the dominating components and the estimation of these components in the original method are benchmarked and scrutinized. It is concluded that the speed dependence of the bilge keels damping is underestimated by the original method. This is partially explained by that Ikeda seems to have underestimated the lift force of the bilge keels in his analytical expressions. Correcting for this and taking account of the lift force-generated pressure on the hull surface gives overall better agreement with model tests. It is also concluded that the hull lift damping component is significantly overestimated with the original method. Non-viscid CFD is used to propose a new generic expression for estimating the lift coefficients for volume carriers which greatly improve the accuracy in comparison to model test results. With these improvements Ikeda's method is revitalized and the applicability is extended to unconventional volume carriers.
\end{abstract}

Keywords Roll damping $\cdot$ Semi-empirical methods $\cdot$ Model tests $\cdot$ Ikeda's method $\cdot$ CFD $\cdot$ Volume carrier

\section{Introduction}

The roll damping of a ship describes the dissipating energy during the roll cycle and is together with the inertia and restoring moment decisive for the roll behaviour at sea and during manoeuvering. For volume carriers vulnerable for parametric roll and synchronous roll excitation sufficient roll damping can be the difference between severe roll angles and a hardly noticeable response. Having a good description of the roll damping is, therefore, crucial to predict critical responses. The damping can be predicted using forced or free model tests as described in IMO [1], full-scale tests as demonstrated by Söder et al. [2] or using computational

Carl-Johan Söder

Carl-Johan.Soder@walleniusmarine.com

Anders Rosén

aro@kth.se

Mikael Huss

mikael.huss@walleniusmarine.com

1 Wallenius Marine AB, PO Box 17086, 10462 Stockholm, Sweden

2 Center for Naval Architecture, Aeronautical and Vehicle Engineering, School of Engineering Sciences, KTH-Royal Institute of Technology, Stockholm, Sweden fluid dynamics (CFD) as shown by Kristiansen et al. [3]. However, for practical reasons semi-empirical methods are the only feasible approach in the early design stage, where simple yet reliable prediction methods for the damping are required.

Ikeda's method [4-12] is the most established semiempirical formulation for roll damping estimation of large vessels and is recommended by ITTC [13]. Ikeda's method is also used as input for vulnerability assessment for parametric roll in the 2nd generation intact stability criteria [14]. Ikeda defined five different roll damping components, friction, wave making, eddy making, hull lift and bilge keel, which were derived based on a combination of theory and systematic model testing using different hull shapes and 2D sections. However, in Kawahara et al. [15] the accuracy of Ikeda's method was found to be unsatisfying for unconventional vessels with high centre of gravity. This was also observed in Söder et al. [2] where the hull lift and bilge keel components were identified as dominating for modern volume carriers and it was concluded that the prediction of these components in particular needs to be improved.

The objective of this paper was to explore the potential for improvements to Ikeda's method for predicting the roll damping of modern volume carriers. Typical characteristics 
for this group of vessels which for instance includes container carriers, Ro-Ro vessels and cruise vessels are slender hull forms and high centre of gravity. Within this group the so-called Pure Car and Truck Carriers (PCTCs) are perhaps the most extreme and in this study three different PCTCs are used as case vessels. The estimation of the bilge keel and hull lift components in the original Ikeda method are benchmarked and scrutinized to identify and propose improvements. Both components are treated in a semi-empirical manner and model tests are performed with the case vessels in various bilge keel configurations and speeds to assess these components. Non-viscid CFD calculations are performed with the case vessels and stretched versions of those to provide input for an improved generic formulation for the hull lift damping component. Implications of the proposed modifications are demonstrated and discussed.

\section{Studied PCTCs}

Three different PCTC designs are used in this study. The designs have state-of-the-art hull lines, slender for minimum resistance combined with high water plane area for maximized form stability. Vessel A is a third-generation Panamax design, delivered in 2011 with cargo capacity corresponding to 8000 equivalent car units which made it the world's largest PCTC at the time of delivery. The second design vessel $\mathrm{B}$ is a first-generation post-Panamax PCTC which currently is in the construction stage. It will have the same cargo capacity but is principally different with respect to Length/Beam $(L / B)$-ratio and Beam/ Draught $(B / D)$-ratio. Together,these designs represent the extremities with respect to $L / B$-ratio among the worldwide ocean going PCTC fleet. Vessel $\mathrm{C}$ is a second-generation Panamax design, delivered in 2007 and is fairly similar to vessel A but has a lower displacement. Two of the vessels are seen in Fig. 1 and general particulars in the design loading condition can be seen in Table 1 .
Table 1 General particulars of vessel A, B and C

\begin{tabular}{llll}
\hline & A & B & C \\
\hline Length $\left(L_{\mathrm{pp}}\right)[\mathrm{m}]$ & 220 & 194 & 220 \\
Beam $[\mathrm{m}]$ & 32.3 & 36.5 & 32.3 \\
Draught $[\mathrm{m}]$ & 10.3 & 9.1 & 9.5 \\
Displacement $\left[\mathrm{m}^{3}\right]$ & 47000 & 35000 & 41000 \\
GM [m] & 1.1 & 1.2 & 1.1 \\
Block coefficient [-] & 0.68 & 0.55 & 0.65 \\
Midship coefficient [-] & 0.93 & 0.92 & 0.93 \\
Scale factor, model [-] & 30 & 30 & 30 \\
\hline
\end{tabular}

\subsection{Model tests}

Model tests have been performed with the vessels presented in Table 1. Vessel A was tested without bilge keels and with continuous bilge keels aligned with the stream lines measuring $0.4 \mathrm{~m}$ and $0.8 \mathrm{~m} \times 0.3 \mathrm{~L}_{\mathrm{pp}}$. Vessel $\mathrm{B}$ was tested without bilge keels and with $0.8 \mathrm{~m} \times 0.3 \mathrm{~L}_{\mathrm{pp}}$ and a pair of unconventional high aspect ratio bilge keels measuring $1.4 \mathrm{~m} \times 0.17 \mathrm{~L}_{\mathrm{pp}}$ which both have the same wetted surface area and thus frictional drag. Vessel $\mathrm{C}$ was tested with bilge keels measuring $0.4 \mathrm{~m}$ and $0.8 \mathrm{~m} \times 0.3 \mathrm{~L}_{\mathrm{pp}}$ only.

The model tests were performed in the towing tank at SSPA Sweden AB in Gothenburg. The roll decay tests were carried out by inclining the model to a heel angle of around $5^{\circ}-10^{\circ}$, keeping it heeled for a moment and then releasing it. This was done at zero speed as well as in different speeds, by towing the model in Froude numbers corresponding to the desired full-scale speeds.

During the tests at speed, the model was towed at constant speed by the carriage through a solid rod attached amidships. The model was kept on course by attaching a connection fore and aft leaving the model free in heave, pitch and roll but restrained in sway and yaw. The towing rod and the connection were located at a height corresponding to the assumed roll axis and attached using joints that are free in rotation.

Fig. 1 The Pure Car and Truck Carriers vessel B in front of vessel $\mathrm{A}$; both are case vessels in this paper

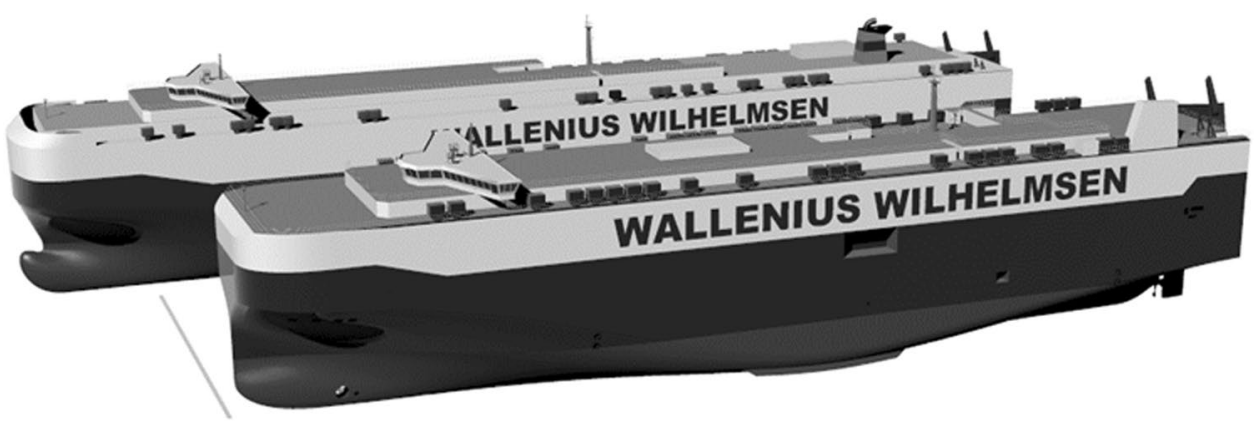


To evaluate the performed tests, a modified version of the PIT approach as developed in Söder et al. [2] is used. The roll equation that is used for the evaluation has a linear-quadratic damping dependence and a linear restoring term according to

$\ddot{\theta}+2 \zeta \omega_{0} \dot{\varphi}+d|\dot{\varphi}| \dot{\varphi}+\omega_{0}^{2} \varphi=0$,

where $\varphi$ is the roll angle, $\omega_{0}$ is the un-damped natural frequency of roll, $\zeta$ is the linear damping coefficient and $d$ is the quadratic damping coefficient.

To conveniently compare results for a certain amplitude the damping is expressed as equivalent linear damping $\zeta_{e}$. At a certain roll amplitude $\varphi_{a}$ this linear equivalent damping gives the same damping over one period as the non-linear damping over the same period. In line with Himeno [16] this equivalent linear damping is calculated as

$\zeta_{e}=\zeta+\frac{4}{3 \pi} d \varphi_{a}$

Figure 2 shows two different roll decay tests performed with the same loading condition and speed but at different amplitude ranges. The linear, quadratic and linear equivalent damping is evaluated as described above. As can be observed the quadratic term is higher for the series initiated at a higher amplitude but the linear term a bit lower. This demonstrates that comparison and extrapolation of test results outside a tested amplitude range is challenging. However, the linear equivalent damping at an amplitude that both series covers (here $2^{\circ}$ ) is very similar which demonstrates that the test and evaluation method provides good repeatability as long as the considered range is covered. Within the tested ranges the standard deviation of the linear equivalent damping is in the magnitude of 0.001 .

\subsection{Hull lift damping}

Ikeda's method as described in Ikeda [9, 12], Himeno [16] and ITTC [13] has been implemented and applied on the studied ships. The bare hull damping is constituted by four different components in Ikeda's method. In Fig. 3 the relative significance of these components is shown for vessel A for roll amplitudes of $2^{\circ}$ and $10^{\circ}$, respectively.

Both the frictional and eddy components are practically zero when the roll amplitude is small but are relatively significant at the lowest speeds when the roll amplitude is large. The linear potential wave damping is not neglectable but is at higher speeds significantly lower than the dominating hull lift component. The predicted damping for both case vessels are compared to model test results for the bare hull in Fig. 4 . As seen, the speed dependence according to Ikeda's method is much stronger than what is shown by the model tests. This indicates that the lift damping component, which constitutes the dominant part of the speed dependence, is overestimated by the method.
Fig. 2 Model scale roll decay tests and evaluated linear-quadratic damping using the modified PIT approach. The linear displayed calculated according to Eq. 2 and the standard deviation $s$ equivalent damping $\zeta_{e}$ at $2^{\circ}$ is
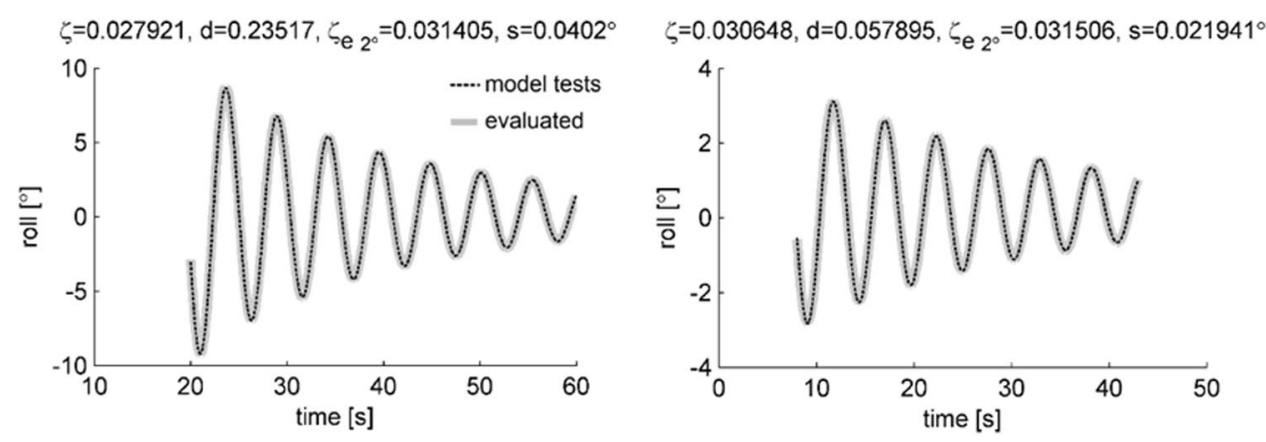

Fig. 3 Results from Ikeda's method for the bare hull of vessel A with the four different damping components; friction, wave, eddy and lift for roll amplitudes of $2^{\circ}$ and $10^{\circ}$
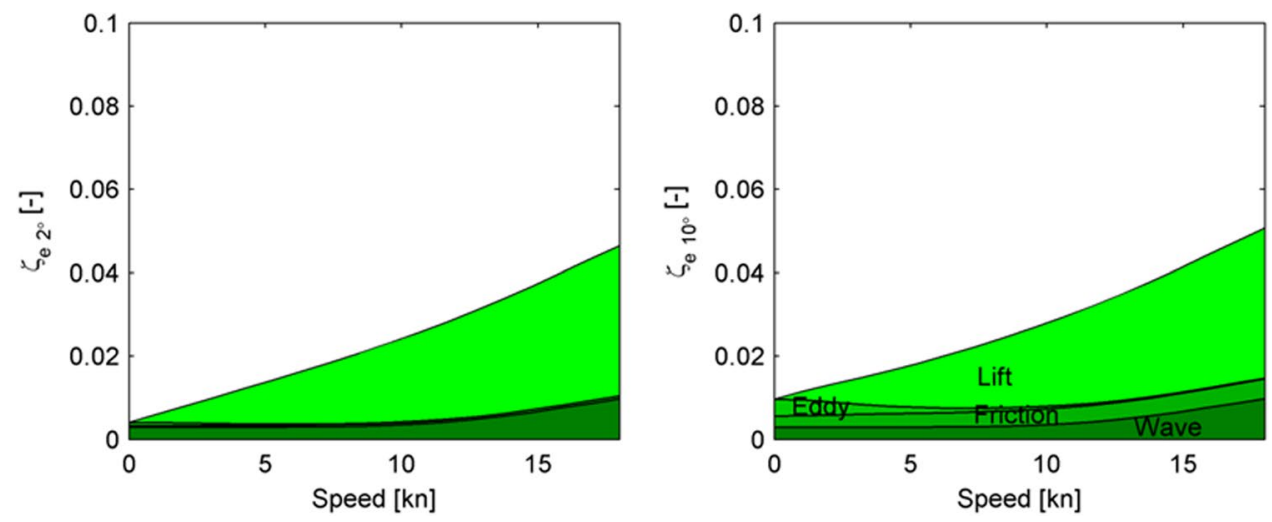
Fig. 4 Predicted damping for vessel A (left) and vessel B (right) in model scale using Ikeda's method and model tests for roll amplitudes of $2^{\circ}, 4^{\circ}, 6^{\circ}$, $8^{\circ}$ and $10^{\circ}$

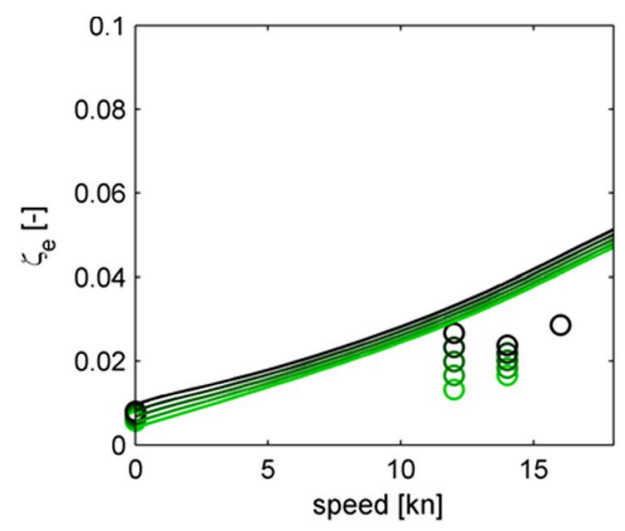

Lift damping is generated as the roll velocity $\dot{\varphi}$ gives the hull an angle of attack $\alpha$ against the forward speed $U$ related incident water flow. This angle of attack is linearly increasing with the distance $l$ from the centre of roll as illustrated in Fig. 5 and, therefore, becomes particularly large for vessels with high centre of gravity. Ikeda made an analogy with lift generated by a twisted plate travelling in a uniform flow, where the incident angle $\alpha$ varies in the vertical direction.

Ikeda's lift damping moment can be written as

$B_{44 L} \dot{\varphi}=q A C_{\mathrm{L}} l_{\mathrm{R}} k_{\overline{O G}}$,

where $q$ is the dynamic pressure due to the forward speed, $A$ is the projected lateral area of the wetted hull, $C_{\mathrm{L}}$ is the lift coefficient of the hull and $l_{\mathrm{R}}$ is the lever of the lift force. $\overline{O G}$ represents the distance from the waterline level to the vertical centre of gravity (defined as negative above the water line) and $k_{\overline{O G}}$ is the ratio between the damping if $\overline{O G}$ is not equal to zero and the damping if $\overline{O G}$ is zero. For volume carriers $\overline{O G}$ is typically not zero.

\subsection{Assessment of $C_{\mathrm{L}}$}

The lift coefficient of the hull is assumed to be linear with the angle of attack and expressed by Ikeda as

$C_{\mathrm{L}}=k_{n} \alpha_{0}=k_{n}\left(\frac{l_{0} \dot{\varphi}}{U}\right)$, where $l_{0}$ represents an effective distance from the centre of roll, at where the local angle of attack $\alpha_{0}$ generates equivalent amount of lift if applied to the hull in a uniform flow as the roll induced lift (see $l_{0}$ and $\alpha_{0}$ in Fig. 5). $k_{n}$ represents the slope of the lift coefficient, $d C_{\mathrm{L}} / d \alpha$ for the hull in a uniform flow. Ikeda [9] used Yumuro's expression, claimed to be taken from the manoeuvering field, to estimate the slope of the lift coefficient for the hull.

$k_{n}=2 \pi \frac{D}{L}+K\left(4.1 \frac{B}{L}-0.045\right)$,

where $K=\left\{\begin{array}{cc}0 & C_{\mathrm{M}} \leq 0.92 \\ 0.1 & 0.92<C_{\mathrm{M}} \leq 0.97 \\ 0.3 & 0.97 \leq C_{\mathrm{M}}<0.99\end{array}\right\}$ and $L, B$ and $d$ is the length, breadth and draught of the vessel, respectively.

For hulls with low midship coefficient $C_{\mathrm{M}}$, such as the case vessels, the lift coefficient is hence given by

$C_{\mathrm{L}}=2 \pi \frac{D}{L} \alpha_{0}$,

which basically correspond to the theoretical lift of a low aspect ratio flat plate. To assess this apparently rough assumption CFD calculations are performed to evaluate the lift coefficients of the two studied hulls. In addition, a flat plate with same length and draught as vessel $\mathrm{A}$ is evaluated for comparative purpose. The calculations consider the hull
Fig. 5 Illustrating the forward velocity $U$, the draft $D$, the roll velocity $\dot{\varphi}$, the distance from the waterline level to the vertical centre of gravity $\overline{O G}$, the effective lever $l_{0}$ where the local angle of attack is $\alpha_{0}$ and the effective lever for the lift force $l_{\mathrm{R}}$

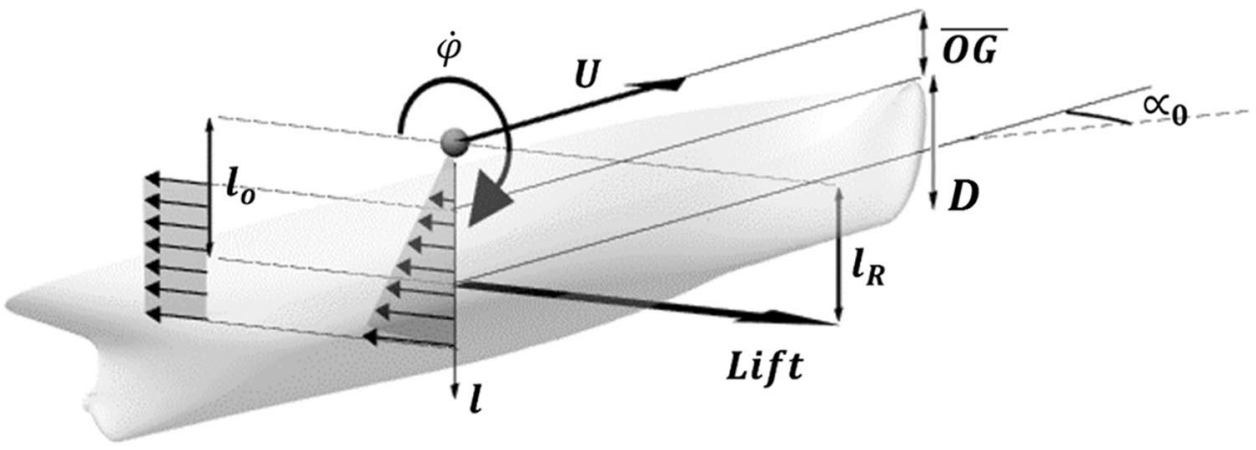


below the water surface only. In the calculations the hull is given a small yaw angle (angle of attack) towards the water flow. As the yaw angle is small non-viscid calculations are used. The calculation domain is shown in Fig. 6. Symmetry boundary conditions are applied on the sides, at the location of the water surface and at the bottom of the domain. The depth of the domain is $7 \times D$.

All calculations are performed for a domain with $6 \cdot 10^{6}$ elements and some calculations were also performed with $2 \cdot 10^{6}$ elements to study the sensitivity of the grid resolution. Figure 7 gives a close up of the fine mesh representing the ship surface for the $6 \cdot 10^{6}$ elements domain.

The calculations are performed at the design draught with a speed of 10 knots and incident angles ranging from $0^{\circ}$ to $5^{\circ}$ which corresponds to yaw angles for normal roll angles. Results are given in Fig. 8. The first observation is that $C_{\mathrm{L}}$ is considerably lower for the hulls than for the plate. The lift coefficient of the hulls is practically linear within the studied range and in the magnitude of 3 times lower than the lift coefficient given by Yumuro's formula which is used in Ikeda's method. It is also observed that the lift coefficient of the plate agrees almost perfectly with the approximation given by Yumuro's formula at the smaller angle of attack. From this it is concluded that the amount of lift generated by the hull is significantly overestimated with Ikeda's model.

The lift coefficients of both hulls appear to be similar but in fact, the lift coefficient of vessel B is some $25 \%$ higher than of vessel A. In Eq. 5 Ikeda formulated $d C_{\mathrm{L}} / d \alpha=k_{n}$ as a function of the $d / L$-ratio and $C_{\mathrm{M}}$ only. However, vessel A and $B$ have practically same draught/length-ratio and midship coefficient. Consequently, Eq. 5 does neither seem to be quantitatively nor qualitatively applicable here.

To provide input for an improved formulation a parametric study is performed investigating how $k_{n}$ is dependent on the main parameters of the hulls. Vessels A and B are used as mother hulls with stretching in length, beam and block and

Fig. 6 Calculation domain and grid used in non-viscid CFD calculations, here showing vessel A with an angle of attack of $5^{\circ}$

Fig. 7 Fine grid resolution used for the fore body of vessel A
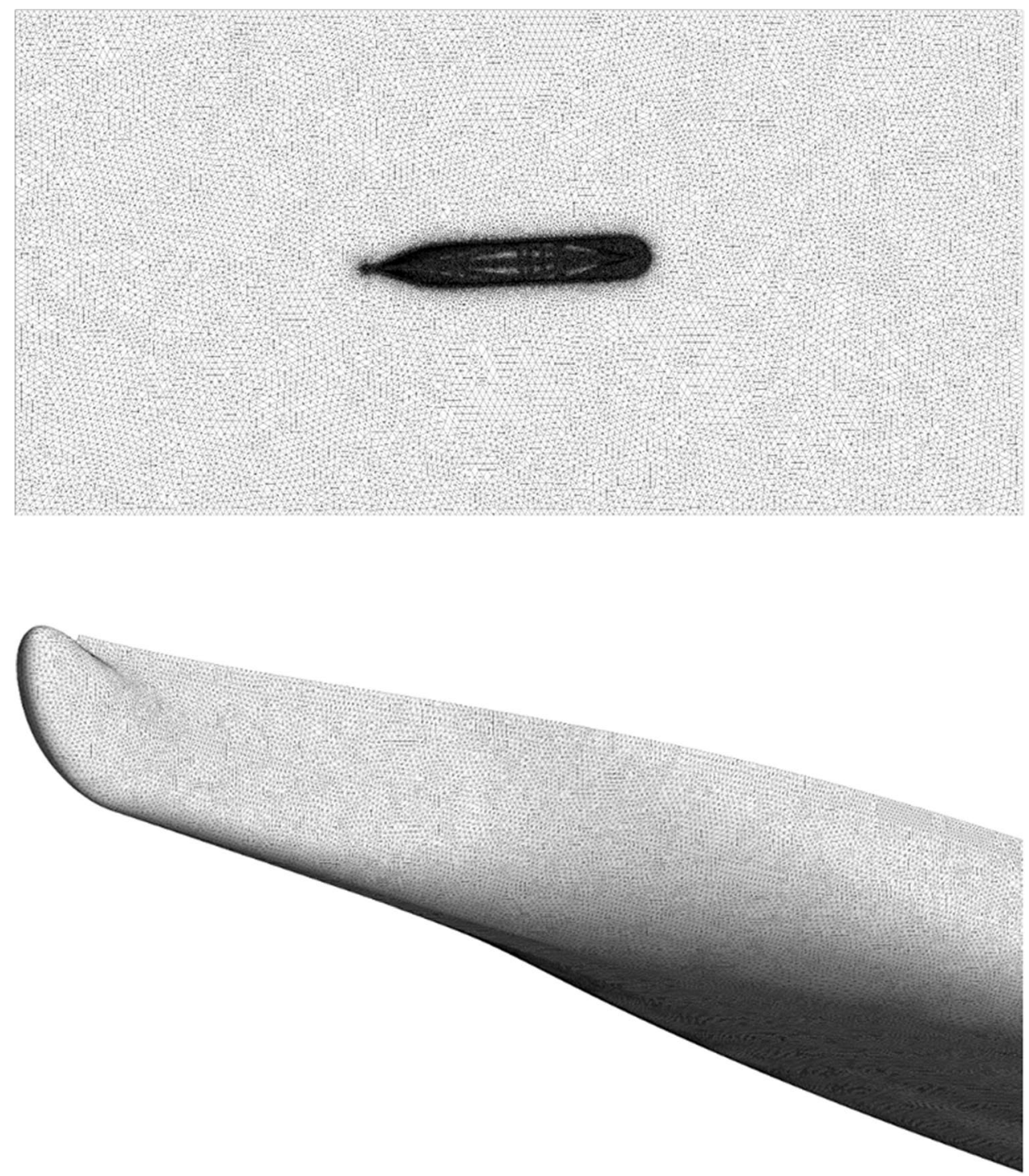
Fig. 8 Evaluated lift coefficients $C_{L}$ vs angle of attach obtained from the CFD calculation

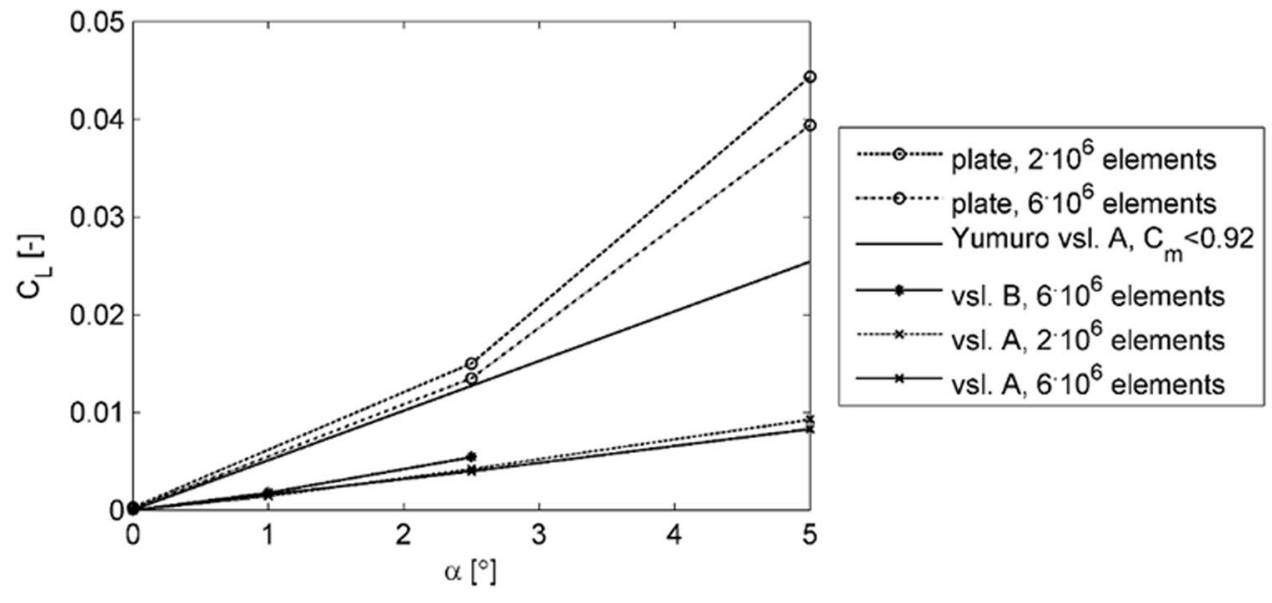

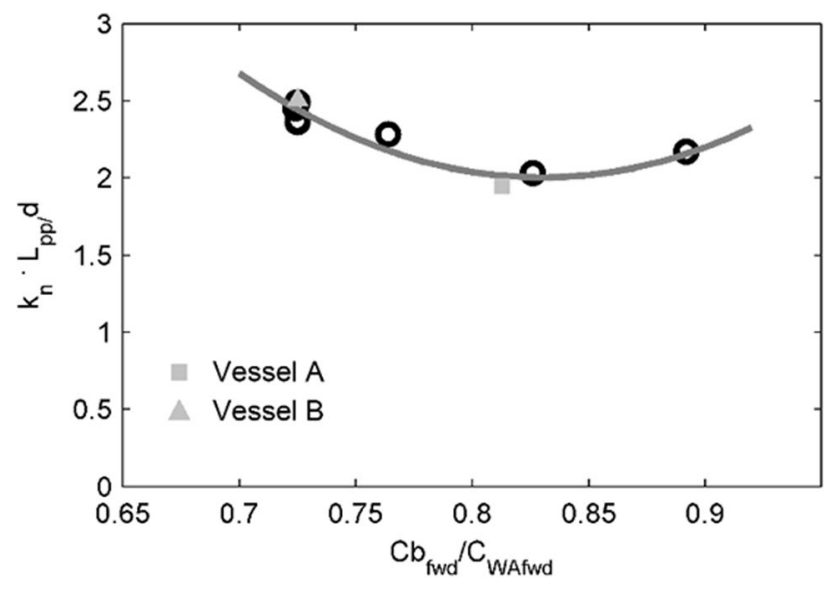

Fig. 9 Evaluated $k_{n}$ against $\frac{C_{b \text { fwd }}}{C_{\text {WAfwd }}}$ for a sample of systematically stretched hull shapes

water plane area coefficients. As previously mentioned the vessels are principally different with respect to $L / B$ - and $B / D$ ratios. In addition, vessel $A$ has a significantly larger block coefficient than vessel B. Vessel A is also more optimized for form stability, meaning that the water plane area coefficient is relatively higher. The two mother vessels together with the stretched clones should hence give a fairly good representation of possible hull shapes of volume carriers.

In line with Eq. 5 the study confirms a linear dependence on the $D / L$-ratio and that beam has neglectable effect on the lift (within reasonable limits). It is also studied how the lift is dependent on the roundness of the sections. In Fig. $9 k_{n}$ normalized with draught/length is plotted against $C_{b \text { fwd }} / C_{W A f w d}$ which is the ratio between the block coefficient in the fore body and the water plane area coefficient in the fore body. This ratio is the vertical prismatic coefficient which basically represents the roundness of the sections.

As seen $k_{n}$ reaches its minimum when $C_{b f w d} / C_{W A f w d} \approx 0.8$ which likely is due to that the hull sections have roundest shapes in that region, where higher ratio gives more square sections and lower ratio gives more triangular sections. Based on the curve fit in Fig. 9 the following approximation is proposed for estimating the lift slope for volume carriers:

$k_{n}=\frac{D}{L_{\mathrm{pp}}}\left(2+40\left(\frac{C_{b \mathrm{fwd}}}{C_{W A f w d}}-0.83\right)^{2}\right)$.

\subsection{Assessment of $k_{\overline{O G}}, I_{\mathrm{R}}$ and $I_{0}$}

The hull lift and the damping moment generated by the hull lift are strongly dependent on $l_{\mathrm{R}}, l_{0}$ and $k_{\overline{O G}}$ (see Fig. 5). In Ikeda [9] it is described that $l_{\mathrm{R}}$ and $l_{0}$ were derived experimentally in the case of $\overline{O G}=0$ as

$l_{0}=0.3 D$

$l_{\mathrm{R}}=0.5 D$,

and Yomuru estimated $l_{\mathrm{R}}, l_{0}$, in the case $\overline{O G} \neq 0$ as

$l_{0}=-\overline{O G}+0.3 D$

$l_{\mathrm{R}}=-\overline{O G}+0.5 D$,

which corresponds to

$k_{\overline{O G}}=\left[1-\frac{l_{0} \overline{O G}+l_{\mathrm{R}} \overline{O G}}{l_{0} l_{\mathrm{R}}}+\frac{\overline{O G}^{2}}{l_{0} l_{\mathrm{R}}}\right]$,

if $l_{0}$ and $l_{\mathrm{R}}$ are kept according to Eq. 8. In Ikeda [9], however, Eq. 10 was not used. Instead

$k_{\overline{O G}}=\left[1-2 \frac{\overline{O G}}{l_{\mathrm{R}}}+\frac{\overline{O G}^{2}}{l_{0} l_{\mathrm{R}}}\right]$,

was derived by separating the lift damping into a pure roll velocity-related component and a sway-related component. Equations 10 and 11 give practically similar results. However, Ikeda tuned Eq. 11 to 
$k_{\overline{O G}}=\left[1-1.4 \frac{\overline{O G}}{l_{\mathrm{R}}}+\frac{0.7 \overline{O G}^{2}}{l_{0} l_{\mathrm{R}}}\right]$,

based on model test results. This significant reduction in $k_{\overline{O G}}$ was likely an indirect compensation for that $k_{n}$ was so greatly overestimated in Eq. 5. In Fig. 10 the lift damping is calculated according to Eqs. 3 and $4, k_{n}$ according to Eq. 7, the levers $l_{\mathrm{R}}, l_{0}$ according to Eq. 8 , and $k_{\overline{O G}}$ according to Eq. 10. For both vessels satisfying agreement with the actual model tests are now demonstrated and the differences between the two designs are qualitatively well captured. It is here proposed that the hull lift component in Ikeda's method, when applied on volume carriers, should be calculated accordingly.

\subsection{Bilge keel damping}

In Ikeda's original method the bilge keel damping is generated by two components, a normal force component (drag force) and a hull pressure induced component. A third component, bilge keel lift, which is supposed to contain the speed dependence, was added later in Ikeda [12].

The bilge keel effect in the model test is isolated by deducting the evaluated damping of the bare hull from the damping of the hull fitted with bilge keels. In Fig. 11 the bilge keel damping in model scale for vessel A with $0.8 \mathrm{~m} \times 0.3 \mathrm{~L}_{\mathrm{pp}}$ and $0.4 \mathrm{~m} \times 0.3 \mathrm{~L}_{\mathrm{pp}}$ bilge keels (left figure) is compared to the bilge keel damping predicted using Ikeda's method (right figure). In Fig. 12 corresponding plots are made for vessel B with $1.4 \mathrm{~m} \times 0.17 \mathrm{~L}_{\mathrm{pp}}$ and $0.8 \mathrm{~m} \times 0.3 \mathrm{~L}_{\mathrm{pp}}$ bilge keels.

The damping levels of the conventional bilge keels are fairly well predicted by Ikeda's method, especially at zero speed. However, the speed dependence is underestimated in general. This is particularly clear for the unconventional high aspect bilge keels which show a strong speed dependence in the model tests that is not reflected by Ikeda's method which calls for further attention.

\subsection{Normal force component}

The normal force component represents the drag generated by the bilge keels and is in Ikeda [11] estimated as

$B_{44 K N 0}=\frac{8}{3 \pi} \rho r_{1}^{3} \omega_{e} \varphi_{a} b_{\mathrm{bk}} f^{2} C_{\mathrm{D}}$,

where $\rho$ is the water density, $r_{1}$ is the distance from the roll axis to the tip of the bilge keel, $\omega_{e}$ is the natural roll frequency, $\varphi_{a}$ is the roll amplitude and $b_{\mathrm{bk}}$ is the breadth of the bilge keel. $f$ is a tuning factor to account for increased flow velocity at the bilge which Ikeada estimated using experiments according to
Fig. 10 Predicted damping for the bare hull vessel A (left) and $\mathrm{B}$ (right) in model scale using Ikeda's method, but roll damping is estimated with the $k_{n}$ according to Eq. 7, the levers $l_{\mathrm{R}}, l_{0}$ according to Eq. 9 and $k_{\overline{O G}}=1$, compared with model tests for roll amplitudes of $2^{\circ}-10^{\circ}$
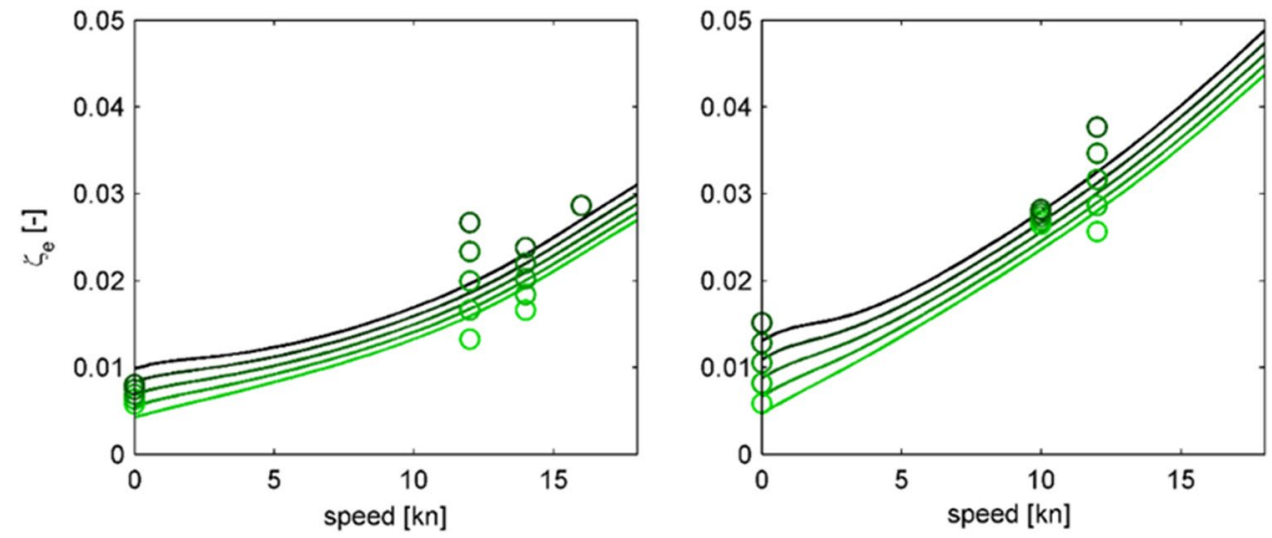

Fig. 11 Left-hand side showing bilge keel damping in model scale for vessel A with $0.8 \mathrm{~m} \times 0.3 \mathrm{~L}_{\mathrm{pp}}$ and $0.4 \mathrm{~m} \times 0.3 \mathrm{~L}_{\mathrm{pp}}$ bilge keels and right-hand side showing corresponding components predicted (in model scale) using Ikeda's method for roll amplitudes of $2^{\circ}-10^{\circ}$
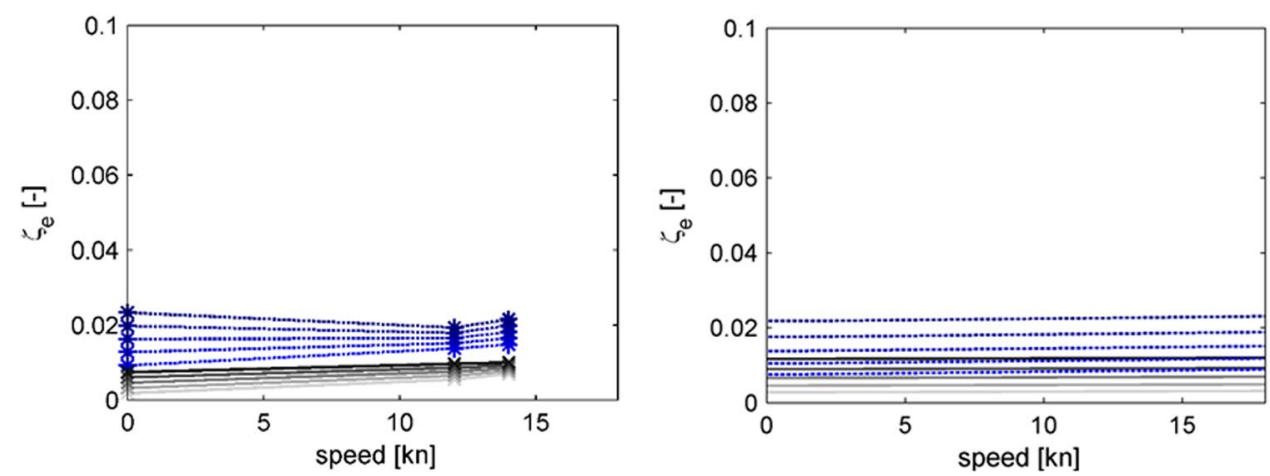
Fig. 12 Left-hand side showing bilge keel damping in model scale for vessel B with $1.4 \mathrm{~m} \times 0.17 \mathrm{~L}_{\mathrm{pp}}$ and $0.8 \mathrm{~m} \times 0.3 \mathrm{~L}_{\mathrm{pp}}$ bilge keels and right-hand side showing corresponding components predicted (in model scale) using Ikeda's method for roll amplitudes of $2^{\circ}-10^{\circ}$
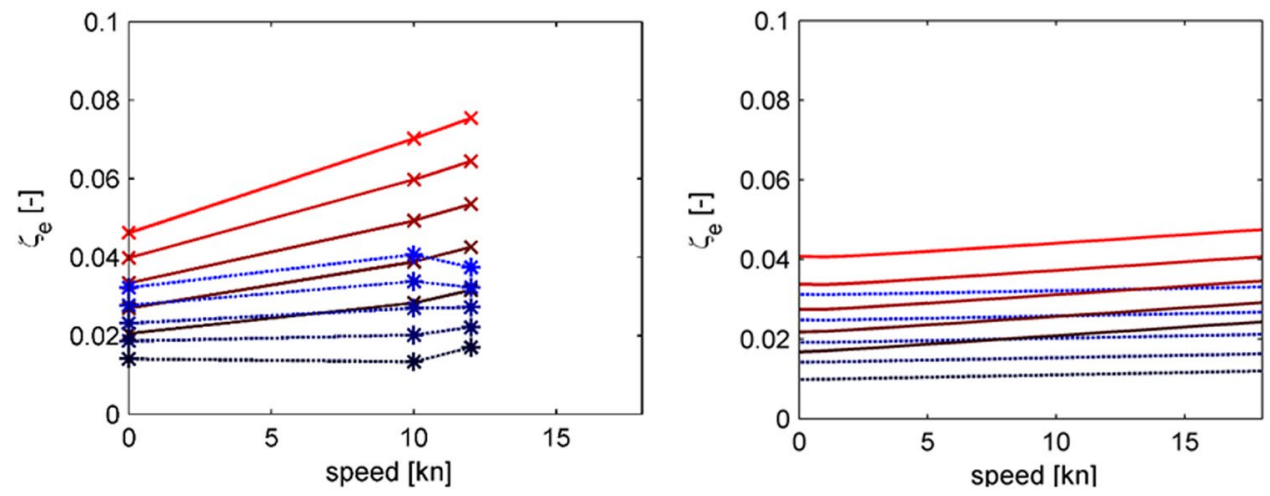

$f=1+0.3 e^{-160(1-\sigma)}$,

where $\sigma$ is the sectional area coefficient of the hull at the bilge keel position. For vessels with small mid ship coefficients (such as PCTCs) this correction factor practically becomes 1 . Ikeda assumed that the drag coefficient $C_{\mathrm{D}}$ is dependent on the Keulegan-Carpenter number which describes the relation between inertia and drag forces of oscillating bodies. The number is defined as $K_{\mathrm{C}}=\frac{V T}{b}$ where $V$ is velocity of the motion, $T$ is the period of the motion and $b$ is the maximum projected breadth. If substituting $V, T$ and $b$ to $l \varphi_{a} \omega, 2 \pi / \omega$ and $2 b_{\mathrm{bk}}, K_{\mathrm{C}}=\frac{\pi l \varphi_{a}}{b_{\mathrm{bk}}}$ is achieved. Ikeda used free roll decay with an ellipsoid fitted with bilge keels to derive $C_{\mathrm{D}}\left(K_{\mathrm{C}}\right)$ and came up with the following estimate for a pair of bilge keels:

$C_{\mathrm{D}}=22.5\left(\frac{1}{K_{\mathrm{C}}}\right) \frac{1}{f}+2.4$.

\section{Lift component}

Ikeda added a non-dimensional lift force component to the bilge keels (2004) according to

$\hat{B}_{B K L}=\frac{\pi r_{2}^{2} b_{\mathrm{bk}}^{2} U}{B^{2} \nabla} \sqrt{\frac{B}{2 g}}$,

where $r_{2}$ is the distance between the roll axis and the centre of the bilge keels and $g$ is the gravity. This can be re-written in dimensional form according to

$B_{B K L}=\rho \pi r_{2}^{2} b_{\mathrm{bk}}^{2} U$ or

$B_{B K L}=\frac{\rho}{2} \cdot \frac{\pi b_{\mathrm{bk}}}{l_{l}} \cdot b_{\mathrm{bk}} l_{l} \cdot r_{2}^{2} U \cdot 2$.

In this formulation $l_{l}$ is the length of the bilge keels and $\frac{\pi b_{\mathrm{bk}}}{l_{l}}$ represents the slope of the lift coefficient of the bilge keels. For low aspect ratio wings, however (with only one free tip), according to Prandtl's lifting line theory, the slope of the lift coefficient could be estimated as $2 \pi \frac{b_{\mathrm{bk}}}{l_{l}} \alpha_{0}$. Thus,

Ikeda seems to have underestimated the lift force of the bilge keels by a factor 2 . The formulation of the lift force-related damping generated by the bilge keels is, therefore, proposed to be updated to

$B_{B K L}=2 \rho \pi r_{2}^{2} b_{\mathrm{bk}}^{2} U$.

\subsection{Pressure component}

The pressure-induced component is in Ikeda estimated as

$B_{44 K H 0}=\frac{4}{3 \pi} \rho r_{1}^{2} f^{2} \omega_{e} \varphi_{a} I$,

where $I$ represents the bilge keel-generated pressure integrated over the hull surface which is estimated as

$I=D^{2}\left(-A \cdot C_{p}^{-}+B \cdot C_{p}^{+}\right)$.

$A$ and $B$ here are semi-empirically derived functions of the hull geometry. $C_{p}^{-}$and $C_{p}^{+}$represents pressure coefficients of the front and the back of the bilge keel. Ikeda assumed that the difference between those two is equal to the drag coefficient $C_{\mathrm{D}}$ of the bilge keel. The positive coefficient was determined experimentally as $C_{p}^{+}=1.2$ which gives the negative coefficient as

$C_{p}^{-}=1.2-C_{\mathrm{D}}$

At the time Ikeda derived these pressure coefficients the forward speed effect was neglected. However, it is likely that the lift force acting on the bilge keels will generate a corresponding pressure field to the hull surface as the drag force. The pressure components are, therefore, here proposed to be modified so that the pressure on the hull surface from lift is included according to

$C_{p}^{-}=1.2-C_{\mathrm{D}}-C_{l p}$.

Following Eq. 13 the drag coefficient is defined as

$C_{\mathrm{D}}=B_{44 K N 0} \frac{1}{\rho r_{1}^{3} \omega_{e} \varphi_{a} b_{\mathrm{bk}} f} \cdot \frac{3 \pi}{8}$. 
For consistency $C_{l p}$ has to be calculated in analogy which yields

$C_{l p}=B_{44 \mathrm{bk} L} \frac{1}{\rho r_{1}^{3} \omega_{e} \varphi_{a} b_{\mathrm{bk}} f^{2}} \cdot \frac{3 \pi}{8}$.

The bilge keel component estimated with updated lift component according to Eq. 19 and pressure component using Eqs. 20, 21 and 23-25) is shown in Figs. 13 and 14. By comparing these results with Figs. 11 and 12 it is demonstrated that that overall better agreement with the model tests is achieved. The speed dependence is now significantly stronger and qualitatively well in line with the model tests for the different bilge keel configurations in general and for the high aspect bilge keels in particular.

\subsection{Implications}

To highlight the implications of the proposed modifications in this paper a parametric roll simulation is performed for a third PCTC, vessel C (described in Table 1) with bilge keels of $0.4 \mathrm{~m} \times 0.3 \mathrm{~L}_{\mathrm{pp}}$ with roll damping predicted both according to the original method and by using the proposed modifications. These predictions along with model test results are given in Fig. 15. Notably the modified method provides significantly better agreement with the model tests.

The parametric roll simulation performed in Fig. 16 corresponds to a real case that occurred with vessel $\mathrm{C}$, described in Rosén et al. [17]. The vessel was fully loaded, steaming in about $10 \mathrm{kn}$ in following waves with significant wave height of around $4 \mathrm{~m}$. The restoring moment representing the sea state during the event is modelled using irregular GM-variations calculated using a hybrid non-linear sea keeping code as described in Söder et al. [18]. Waves are modelled using 200 equidistant frequency components with

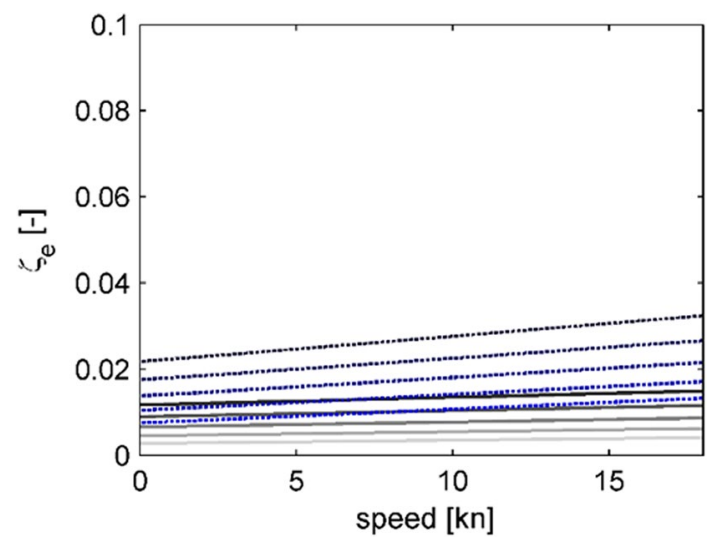

Fig. 13 Bilge keel damping in model scale for vessel A with $0.8 \mathrm{~m} \times 0.3 \mathrm{~L}_{\mathrm{pp}}$ and $0.4 \mathrm{~m} \times 0.3 \mathrm{~L}_{\mathrm{pp}}$ bilge keels using the here proposed modified Ikeda's method

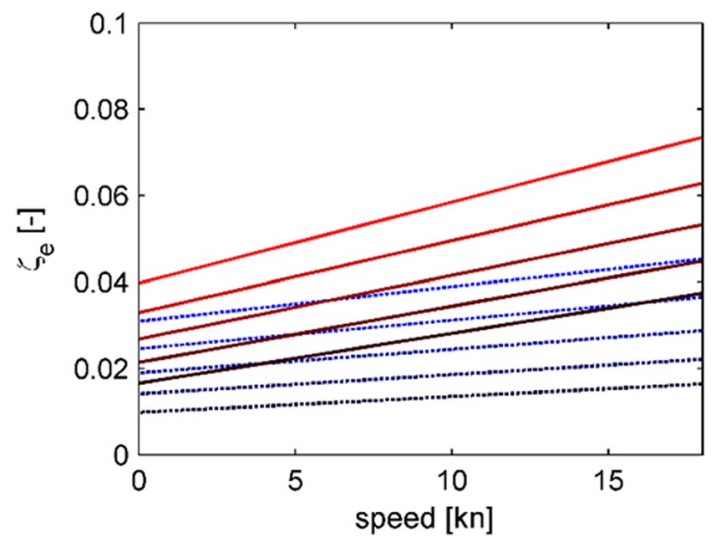

Fig. 14 Bilge keel damping in model scale for vessel $B$ with $1.4 \mathrm{~m} \times 0.17 \mathrm{~L}_{\mathrm{pp}}$ and $0.8 \mathrm{~m} \times 0.3 \mathrm{~L}_{\mathrm{pp}}$ bilge keels predicted using the here proposed modified Ikedas method

randomly selected phases and a small initial disturbance in roll is applied to the simulation. A time sequence which includes a parametric roll event is selected and used for this roll damping comparison.

The simulations demonstrate that the different damping input results in a striking difference in roll response. When the damping is predicted with the original Ikeda the roll motions are small while on the contrary large-amplitude rolling is obtained when the simulations are performed with the modified method. This clearly highlights the importance of having an accurate description of the roll damping and that a non-conservative estimate of the roll damping can result in that a potentially critical situation not is detected.

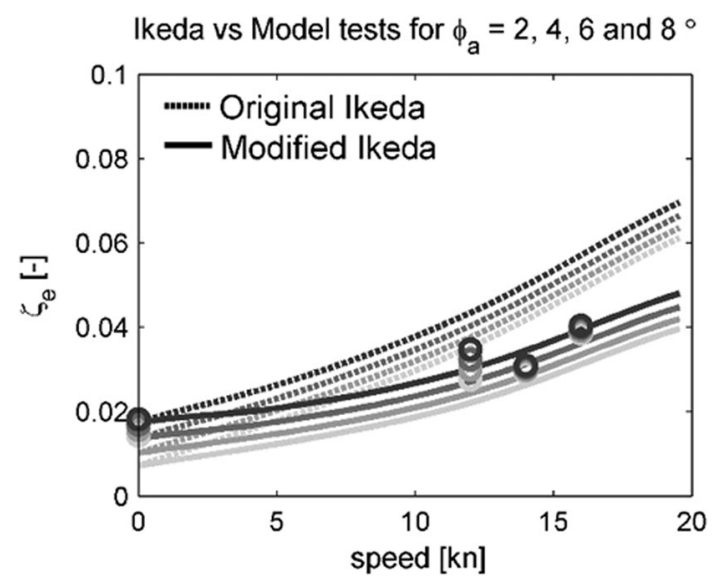

Fig. 15 Predicted damping for vessel C using Ikeda's method and modified Ikeda's method compared to model tests for roll amplitudes of $2^{\circ}-8^{\circ}$ 

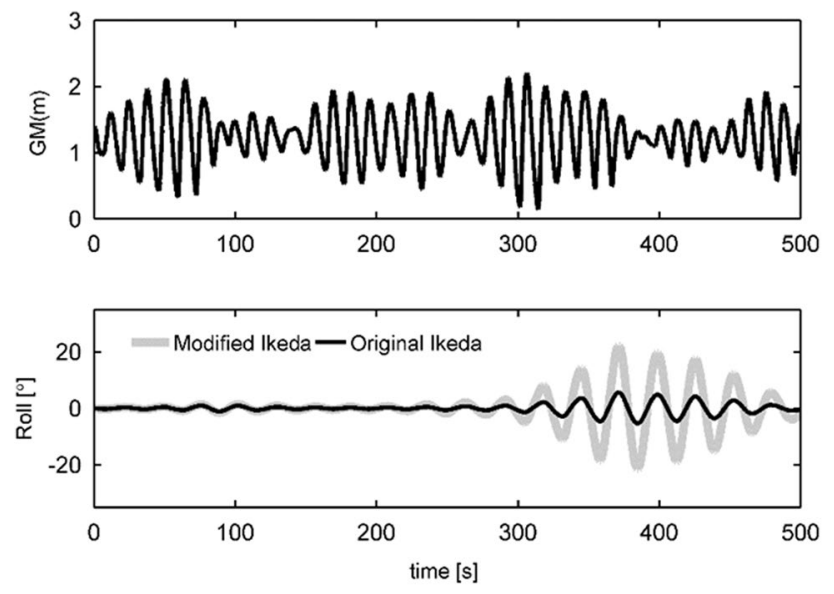

Fig. 16 GM-variations and roll responses from simulations of parametric roll due to $2: 1$ resonance in $4 \mathrm{~m}$ following waves

\section{Discussion}

The results in this paper demonstrates how relatively minor updates of Ikeda's method can greatly improve the accuracy of the roll damping prediction of volume carriers and related roll responses. The study is, however, limited to a few case vessels and an experimental setup with some practical and theoretical limitations.

A problem with the roll decay tests performed at speed is that the towing tank, although it is $260 \mathrm{~m}$ long, is not long enough to allow the model to cover the desired amplitude range of $10^{\circ}-1^{\circ}$ before it has reached the end of the tank. This is especially a problem when the damping is low as for the bare hulls where in the worst cases only a range of barely $2^{\circ}$ could be covered for a single run. For comparison with semi-empirical results, e.g. Figure 10 the non-linearity of the model tests is extrapolated outside the tested range. As previously highlighted this introduces undesired uncertainties and is the likely cause to the inconsistent amplitude dependence between the different speeds that is observed in the figure. Most runs, however, covered amplitudes around $4^{\circ}$ so the linear equivalent damping for $\varphi_{a}=4^{\circ}$ should be considered as the most relevant for quantitative comparisons. For future studies, forced roll decay tests or multiple free roll decay tests which together cover the considered range, could preferably be performed.

When performing CFD calculations for ship hulls, domain size and number of elements quickly hit the limit for what a personal computer can handle. Variations in element size demonstrated that the selected size is satisfying for this study. The influence from the choice of the computational domain and the boundary conditions were, however, not studied in detail here and could be given further attention in further studies.

The parameter variation of the hull shapes that resulted in the proposed formula for estimating hull lift in Eq. 7 was limited to modest variations of the hull shapes. The hypothesis prior to the variations was that the roundness of the sections is the most decisive factor for the lift and the variations confirmed that. The study could, however, preferably be extended to cover additional hull-specific coefficient, as well as to include other kind of hull shapes than PCTCs only.

The results showed a dramatic difference in efficiency for the so-called un-conventional high aspect ratio bilge keels which thus appears as an attractive way to improve the damping since they do not give any penalty in wetted area. In Söder et al. [19], it was highlighted how bilge keels in model scale may be subjected to substantial scale effects due to the relatively higher boundary layer thickness in model scale. If that is the case, deeper bilge keels should be less subjected to these effects which would introduce bias in bilge keel depth efficiency studies using model scale tests.

\section{Conclusions}

An accurate description of the roll damping is crucial for prediction of critical roll responses such as parametric roll. Sufficient damping can be the difference between a severe roll response and a hardly noticeable response. In this paper Ikeda's method for roll damping estimation has been revisited. The applicability of the method to modern volume carriers in particular has been considered. For volume carriers the hull lift and bilge keel components are the dominating components and the estimation of these components in the original method has been benchmarked and scrutinized and improvements have been proposed. Both components were treated in a semi-empirical manner. Model tests were performed with two Pure Car and Truck Carriers (PCTCs) which served as case vessels, in various bilge keel configurations and speeds to assess the hull lift and bilge keel components.

The bilge keel effect was isolated from model tests by deducting the evaluated damping of the bare hull from the damping of the hull fitted with bilge keels. The damping levels of conventional bilge keels were well predicted by Ikeda's original method at zero speed. However, the speed dependence of the bilge keel damping is underestimated by Ikeda's original method. It was found that this could partially be explained by that Ikeda seems to have underestimated the lift force of the bilge keels in his analytical expressions. Correcting for this and taking account of the lift force-generated pressure on the hull surface gives overall better agreement between predictions and model tests and is, therefore, proposed for future applications.

It was also concluded that the hull lift damping component is significantly overestimated with Ikeda's method. Non-viscid CFD calculations performed suggest that the lift 
coefficient of the hull is overestimated by the magnitude of a factor three in the original method when applied on the case vessels. Systematic stretching of the hull shapes of the case vessels was performed to investigate how the lift coefficient is dependent on the hull particulars. Based on the findings a generic expression was proposed for estimating the lift coefficients for volume carriers. When applied together with Yomuru's original expressions for the levers of the lift force and the effective angle of attack, satisfying agreement with the actual model tests was demonstrated both qualitatively and quantitatively.

The paper shows that the proposed modifications greatly improve the accuracy of the roll damping prediction of volume carriers and thus the prediction of critical roll responses. With these improvements Ikeda's method is re-vitalized and the applicability is extended to un-conventional volume carriers - a class of vessel that is particularly dependent on accurate roll damping prediction, given their high vulnerability to critical rolling events and the ongoing development in IMO with the 2nd generation intact stability criteria.

Acknowledgements This research has been financially supported by the Swedish Mercantile Marine Foundation (Stiftelsen Sveriges Sjömanshus) and the Swedish Maritime Administration (Sjöfartsverket) which are both gratefully acknowledged.

Open Access This article is distributed under the terms of the Creative Commons Attribution 4.0 International License (http://creativecommons.org/licenses/by/4.0/), which permits unrestricted use, distribution, and reproduction in any medium, provided you give appropriate credit to the original author(s) and the source, provide a link to the Creative Commons license, and indicate if changes were made.

\section{References}

1. IMO (2006) Interim Guidelines for Alternative Assessment of the Weather Criterion, MSC.1/Circ. 1200

2. Söder et al. (2012) Assessment of ship roll damping through full scale and model scale experiments and semi-empirical methods. In: proceedings of the 11th international conference on the stability of ships and ocean vehicles, 23-28 September 2012, Athens, Greece (Söder et al. 2016)

3. Kristiansen et al. (2014) Experimental and numerical investigation of ship roll damping with and without bilge keels. In: proceedings of the ASME 2014 33rd international conference on ocean, offshore and arctic engineering OMAE2014 June 8-13, 2014, San Francisco, California, USA

4. Ikeda Y, Himeno Y, Tanaka N (1976) On roll damping force of ship: effects of friction of hull and normal force of bilge keels. J Kansai Soc Naval Archit Jpn 161:41-49 (in Japanese)

5. Ikeda Y, Himeno Y, Tanaka N (1977) On eddy making component of roll damping force on naked hull. J Soc Naval Archit Jpn 142:54-64 (in Japanese)

6. Ikeda Y, Komatsu K, Himeno Y, Tanaka N (1977) On roll damping force of ship effects of hull surface pressure created by bilge keels. J Kansai Soc Naval Archit 165:31-40 (in Japanese)

7. Ikeda Y, Himeno Y, Tanaka N (1978) Components of roll damping of ship at forward speed. J Soc Naval Archit Jpn 143:113-125 (in Japanese)

8. Ikeda Y, Himeno Y, Tanaka N (1978) On eddy making component of roll damping force on naked hull. Report of Department of Naval Architecture University of Osaka Prefecture, No. 00403

9. Ikeda Y, Himeno Y, Tanaka N (1978) Components of roll damping of ship at forward speed. Report of Department of Naval Architecture University of Osaka Prefecture, No. 00404

10. Ikeda Y, Himeno Y, Tanaka N (1978) A prediction method for ship roll damping. Report of Department of Naval Architecture University of Osaka Prefecture, No. 00405

11. Ikeda Y, Komatsu K, Himeno Y, Tanaka N (1979) On roll damping force of ship-effects of hull surface pressure created by bilge keels. Report of Department of Naval Architecture University of Osaka Prefecture, No. 00402

12. Ikeda Y (2004) Prediction methods of roll damping of ships and their application to determine optimum stabilization devices. J Mar Technol 41(2):89-93

13. ITTC (2011) ITTC recommended procedures numerical estimation of roll damping. In: international towing tank conference, report 7.5-02-07-04.5

14. IMO (2016) Draft explanatory notes on the vulnerability of ships to the parametric roll stability failure mode, SDC 3/WP.5, Annex 4

15. Kawahara et al. (2009) A simple prediction formula of roll damping of conventional cargo ships on the basis of Ikeda's method and its limitation. In: proceedings of the 10th international conference on stability of ships and ocean vehicles, Saint Petersburg, Russia

16. Himeno Y (1981) Prediction of ship roll damping- state of the art. The University of Michigan College of Engineering, No. 239

17. Rosén A, Huss M, Palmquist M (2012) Experience from parametric rolling of ships. In: Fossen TI, Nijmeijer H (eds) Parametric resonance in dynamical systems. Springer, New York

18. Söder C-J, Rosén A, Ovegård E, Kuttenkeuler J, Huss M (2013) Parametric roll mitigation using rudder control. J Mar Sci Technol. 18:395-403. https://doi.org/10.1007/s00773-013-0216-3

19. Söder C-J, Rosén A (2016) A framework for holistic roll damping prediction. In: Proceedings of the 15th International Ship Stability Workshop, 13-15 June 2016, Stockholm, Sweden 